\title{
PREVENTIVE MAINTENANCE STRATEGY OPTIMIZING MODEL UNDER TWO-DIMENSIONAL WARRANTY POLICY
}

\section{MODEL OPTYMALIZACJI STRATEGII KONSERWACJI ZAPOBIEGAWCZEJ W WARUNKACH DWUWYMIAROWEJ POLITYKI GWARANCYJNEJ}

\begin{abstract}
An effective warranty servicing strategy should be made considering both warranty cost and product availability. Based on the two-dimensional free repair warranty, a strategy combining the imperfect preventive maintenance and minimal repair is proposed where the imperfect preventive maintenances are implemented in a special subregion of the warranty and all other failures are repaired minimally. By modeling the warranty cost and product availability, we derive the optimum warranty servicing strategy and corresponding parameters to minimize the cost-effective of unit time. Finally, we provide a numerical illustration and a comparison with some other strategies.
\end{abstract}

Keywords: two-dimensional warranty, imperfect preventive maintenance, availability.

\begin{abstract}
Efektywna strategia obstugi gwarancyjnej powinna uwzględniać zarówno koszty gwarancji jak i dyspozycyjność produktu. W oparciu o pojęcie dwuwymiarowej gwarancji bezpłatnej naprawy, zaproponowano strategię łączaca niepetna konserwację zapobiegawcza z naprawa minimalna, gdzie działania obstugowe w ramach niepetnej konserwacji zapobiegawczej przeprowadza się w ramach specjalnego podobszaru gwarancji, a wszelkie inne uszkodzenia naprawia się w ramach naprawy minimalnej. Modelujac koszty naprawy oraz dyspozycyjność produktu, wyprowadzono optymalna strategię obstugi gwarancyjnej oraz odpowiadajace jej parametry w celu zminimalizowania kosztów na jednostkę czasu. Na koniec, proponowane rozwiązanie zilustrowano na przykładzie numerycznym oraz porównano z innymi strategiami.
\end{abstract}

Stowa kluczowe: gwarancja dwuwymiarowa, niepetna konserwacja zapobiegawcza, dyspozycyjność.

\section{Introduction}

A warranty servicing strategy has significant impact on manufacturer's warranty cost and the product availability. As requirement of consumers for the quality of products is increasing, product availability will obviously affect consumer satisfaction and the reputation of manufacturer and then the product sales, so reasonable warranty strategy should be made considering both warranty cost and product availability to meet the interests of both sides.

Preventive maintenance could reduce the product failure rate so that reduce the warranty cost and improve availability effectively. With the updating of warranty policy, warranty cost model under the preventive maintenance is developed in many studies. Chun [2] introduced the periodic preventive maintenance in prior time when he studied product warranty. This model is generalized by Jack and Dagpunar [7], where the product can be repaired "as good as new" after preventive maintenance, and preventive maintenance period is variable. Yeh and Lo [12] extends the model with making the preventive maintenance degree reach some specific level to minimize the warranty cost. The study [4] derives an optimal preventive warranty strategy to minimize the product's long term expected cost by balancing the saving and added cost by preventive maintenance during warranty period, and obtains the optimal preventive maintenance period and puts forward effective algorithm. The above studies introduce preventive maintenance into the one-dimensional warranty policy and are aimed at getting the lowest warranty cost without considering the product availability. In addition, preventive maintenance is not always effectively, as the new product just begins to operate, unreasonable preventive maintenance often leads to a high warranty cost and low availability since the failure rate is relatively low at the beginning of exploitation.

A summary of the different warranty policies is given in [1]. They can be divided into one-dimensional and two-dimensional policies broadly. For the study of optimizing models under two-dimensional warranty, Iskandar and Murthy [6] proposed a repair-replacement strategy with two subregions to optimize the warranty cost, where minimal repair and replacement strategy is adopted in different subregions. In [5], the strategy in [6] is improved to a new repair-replacement strategy with three subregions, where the first failure in the middle subregion $\Omega_{2}$ will be handled by replacement, and the remaining failures are all repaired minimally. The strategy in [5] is improved to an imperfect repair strategy by Yun and Kang [13], where the first repair in the middle subregion is imperfect, and all remaining repairs are minimal, and then, this strategy is generalized to an n-subregion strategy by Varnosafaderani and Chukova $[10,11]$, where the first repair in each intermediate subregions $\left(\Omega_{2}-\Omega_{\mathrm{n}-1}\right)$ are imperfect, and other failures are repaired minimally. The above studies mentioned are aimed at optimizing the warranty cost without considering the preventive maintenance and product availability, but the availability, like warranty cost, is also an important factor to influence the warranty strategy because it is related to consumer satisfaction, especially for some specific customer as army. 
In view of the above analysis, this paper introduces the minimalimperfect preventive maintenance combination strategy considering a product with a two-dimensional free repair warranty and presents a mathematical optimization model to derive the optimal preventive maintenance strategy in the warranty period with respect to the warranty cost and product availability.

\section{Warranty servicing strategy}

The product is sold with a two-dimensional free repair warranty. As mentioned in earlier research, the two-dimensional warranty is characterized by a region $\Omega$ in a two-dimensional plane and the repair is free to consumer in this region [6].

In this paper, the case where warranty region $\Omega$ is a rectangle with the age limit $K$ and usage limit $L$ is studied, and the warranty expires when either limit is exceeded. The minimal - imperfect preventive maintenance combination strategy is introduced to deal with the failure in warranty region. The warranty servicing strategy is implemented as follows.

Firstly, as in [6], the warranty region $\Omega[(0, \mathrm{~K}) \times(0, \mathrm{~L})]$ is divided into two disjoint subregions $\Omega_{1}$ and $\Omega_{2}$, as shown in Fig. 1 . The shapes of the subregions are governed by a rate parameter $r(r \geq 0)$, such that

$$
r 1=\frac{L 1}{K 1}, \quad r 2=\frac{L}{K}
$$

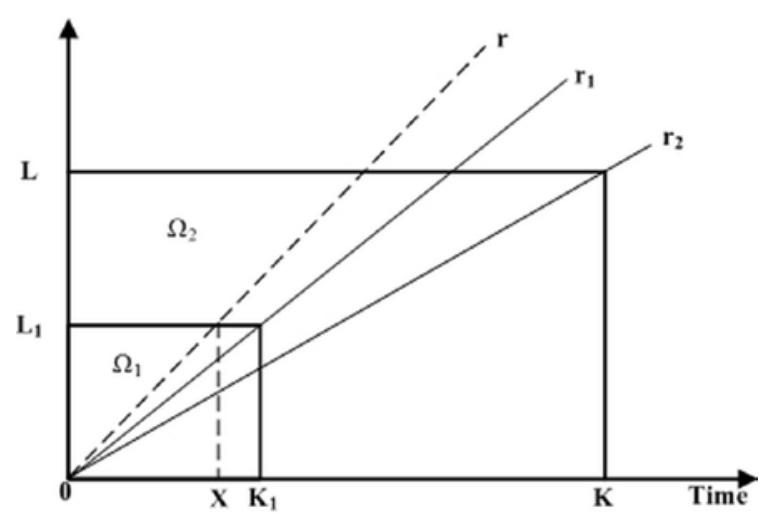

Fig. 1. Subregions of the warranty region

Then, given the subregions $\Omega_{1}$ and $\Omega_{2}$, the minimal - imperfect preventive maintenance combination strategy is as follows:

(a) all repairs in $\Omega 1$ are minimal with cost $\mathrm{Cf}$ and duration $T_{f}$.

(b) The first imperfect preventive maintenance is taken at the time point the warranty over the subregion $\Omega_{1}$ expires, and periodic preventive maintenance (PM) is implemented in $\Omega_{2}$ with cost $C_{p}$, duration $T_{p}$ and period $T$, and the remaining failures are rectified by minimal maintenance.

The warranty policy introduced above is of certain practical significance. In the subregion $\Omega_{1}$, the failure rate is relatively low since the product just begins to operate, so minimal repair is effective. PM strategy is adopted in $\Omega_{2}$ since the failure rate rises with the increase of the product's age/usage, and the proper PM action can reduce the shutdown loss and maintenance cost caused by failure. In practice, having a combination of the minimal repair and PM often leads to lower warranty servicing cost and higher product availability.

\section{Modeling product failure and imperfect mainte- nance}

Two different approaches have been used to model the product failure process for the analysis of two-dimensional warranty policies. They are one-dimensional and two-dimensional approaches, and the detailed description has been introduced in related literature [8]. In this study, the failure process under two dimensions is modeled using the one-dimensional approach.

In the one-dimensional approach, product usage is considered as a function of the age of the product. Assuming that the relationship is linear with a nonnegative coefficient $R$, such that

$$
U(t)=R T(t),
$$

where $U(t)$ and $T(t)$ are the usage and age of the product at time $t$, and the usage rate $R$ is a nonnegative random variable with a known distribution function $G(r)$. When no product failure occurs before $t$ or all the failures are repaired, then $T(t)=\mathrm{t}$. However, if the product is not repairable and the failure product must be replaced by a new one, then $T(t)<t$. For details, see [6].

Product failures are modeled by a stochastic process with an intensity function dependent on age and usage of the product. Given a usage rate $r$, the intensity function will have a single variable $t$ since the usage can be conveyed by age, such that

$$
\lambda(t \mid r)=\varphi(T(t), U(t))
$$

With the simplest being a polynomial of order one [6], the following conditional intensity function form is given by:

$$
\lambda(t \mid r)=\theta 0+\theta 1 r+\theta_{2} T(t)+\theta 3 U(t)
$$

and a polynomial of order two is given in [5], as follows:

$$
\lambda(t \mid r)=\theta_{0}+\theta_{1} r+\theta_{2} T(t)^{2}+\theta_{3} T(t) U(t),
$$

with the parameters $\theta_{i}>0$.

To model the imperfect preventive maintenance effect on the failure rate of the product, a modification of the "virtual age" model proposed in [3] is introduced, where the effect of an imperfect maintenance is expressed by a reduction of the system virtual age, that is, after preventive maintenance, the failure rate decreases to a former level as the age of the product reduces, and the corresponding former age is the "virtual age" (or effective age).

Given the minimal - imperfect preventive maintenance combination strategy, we introduce the improvement factor $\alpha$, and the virtual age reduction depends on $\alpha$. Based on the model in [3], the failure rate of the product is defined by its virtual age (or effective age), and when an imperfect maintenance is performed on the product, its virtual age will be reduced. Assume that the $j$-th preventive maintenance interval is $\Delta j$, and after the $j$-th imperfect preventive maintenance with improvement factor $\alpha_{j}$, the virtual age reduces by $\alpha_{j} T\left(\Delta_{j}\right)$. So the virtual age after the $j$-th preventive maintenance can be given by:

$$
v_{j}(t)=T(t)-\sum_{i=1}^{j} \alpha_{i} T\left(\Delta_{i}\right) .
$$

Since the product in this study is repairable and all failures are repaired minimally, then $T(t)=t$, and the eq.(3) can be transformed to:

$$
v_{j}(t)=t-\sum_{i=1}^{j} \alpha i \Delta i
$$


so the conditional intensity function after the $j$-th preventive maintenance becomes:

$$
\lambda_{j}(t \mid r)=\lambda\left(v_{j}(t) \mid r\right)=\lambda\left(t-\alpha 1 X-\sum_{i=2}^{j} \alpha_{i} T \mid r\right) \quad \text { with } \sum_{i=2}^{1} \alpha_{i} T=0
$$

where $\lambda(\bullet \mid r)$ is the initial intensity function of the process and $X$ is the time point that the warranty over the subregion $\Omega_{1}$ will expire (see Fig.1). $\alpha i \in[0,1]$ represents the degree of a repair (improvement factors), which is the level of the applied effort to improve the state of product. Based on the model, $\alpha=0$ means that the preventive maintenance is minimal and PM action has no significant effect on the state of the product. Besides, $\alpha=1$ means that the repair is perfect and the state of product is restored to "as good as new" state. The conditional intensity function of the process after an imperfect maintenance is between the conditional intensities after a minimal repair and a perfect repair.

\section{Two-dimensional warranty cost and availability mod- els}

Let $E C^{\Omega}(\varpi)$ and $E A^{\Omega}(\varpi)$ denote the expected warranty cost and availability over the warranty region $\Omega$ respectively, where $\varpi$ represents the parameters of the minimal - imperfect preventive maintenance combination strategy and is given by $\varpi=(K 1, T, r 1)$. We assume that $K 1+T_{p}<K$. Each whole preventive warranty cost is denoted by $C_{p}$, which includes the preventive warranty expected cost and the loss of shutdown. Analogously, each whole failure warranty cost is denoted by $C f$. Consider the following two cases: (a) $r 1 \leq r 2$; (b) $r 1>r 2$. See Fig. 2 .



(a) $r_{1} \leq r_{2}$

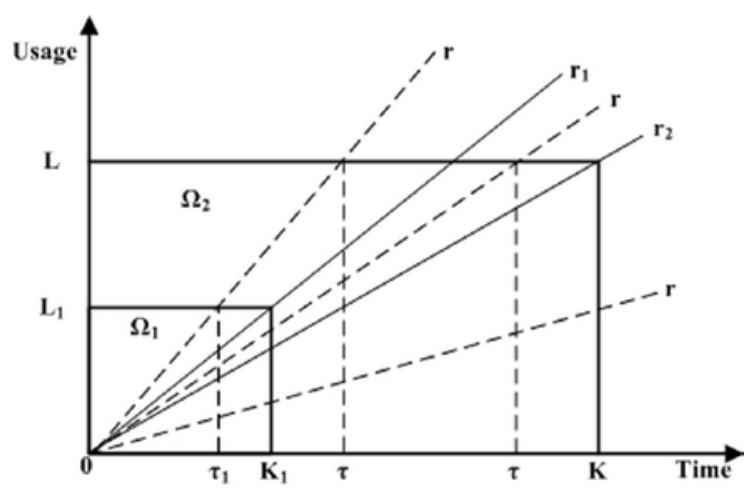

(b) $r_{1}>r_{2}$

Fig. 2. analysis for case (a) and (b)

\subsection{Case (a): $r 1 \leq r 2$}

For this case, the warranty region is divided according $r 1$ and $r 2$, and considering the value of usage rate $R=r$, the following three subcases are discussed:

$$
\text { (a.1) } r \leq r 1 ; \text { (a.2) } r 1<r \leq r 2 ;(\text { a.3) } r 2<r
$$

We denote the expected warranty costs and availability, conditional on $R=r$, for the three subcases by $E C_{r}^{1}(\varpi), E C_{r}^{2}(\varpi)$, $E C_{r}^{3}(\varpi)$ and $E A_{r}^{1}(\varpi), E A_{r}^{2}(\varpi), E A_{r}^{3}(\varpi)$, respectively.

\subsubsection{Case (a.1): $r \leq r 1$}

Cost model: In this case, the warranty over the subregions $\Omega_{1}$ and $\Omega_{2}$ will expire at time points $K_{1}$ and $K$, respectively (see Fig.2). Then the expected warranty cost can be given as follows:

$$
E C_{r}^{1}(\varpi)=C f E N(K 1 \mid r)+n C_{p}+\sum_{i=1}^{n-1} E C f i(T)+E C f n(K 1, K)
$$

where $E N(K 1 \mid r)$ represents failure quantities in the subregion $\Omega_{1} . n$ is the number of imperfect preventive maintenance in the subregion $\Omega_{2} . E C f i(T)$ is the expected cost of minimal repairs in the $i$-th periodic preventive maintenance interval. $E C f n(K 1, K)$ is the expected cost of minimal repairs between $K 1+T_{p}+(n-1)\left(T+T_{p}\right)$ and $K$.

Since failures over $\left[0, K_{1}\right]$ are repaired minimally and no preventive maintenance is implemented, the expected number of minimal repairs in the subregion $\Omega_{1}$ is equal to:

$$
E N(K 1 \mid r)=\int_{0}^{K 1} \lambda(t \mid r) d t .
$$

In general, the duration of a repair is minute relative to preventive maintenance period, so we can neglect the influence and use the eq.(7) to derive approximately expected the number of failure [9].

Periodic imperfect preventive maintenance will be implemented in the subregion $\Omega_{2}$. Given the period of preventive maintenance $T$ and maintenance duration $T_{p}, n$ is expressed by:

$$
n=n(K 1, K \mid r)=\operatorname{int}\left[\left(K-K 1-T_{p}\right) /\left(T+T_{p}\right)+1\right] .
$$

The warranty over the subregion $\Omega_{1}$ will expire at time $K_{1}$, so the the conditional intensity function after the $j$-th imperfect maintenance (the $j$-th preventive maintenance interval) becomes:

$$
\lambda_{j}(t \mid r)=\lambda\left(t-\alpha_{1} K 1-\sum_{i=2}^{j} \alpha_{i} T \mid r\right)
$$

Then, in the $i$-th periodic preventive maintenance interval, failures are rectified by minimal repairs. Then, the numbers of minimal repairs is given by:

$$
E N r(i)=\int_{K 1+(i-1) T+i T p}^{K 1+i(T+T p)} \lambda i(t \mid r) d t
$$

So the total expected cost of the minimal repairs in the $n$ preventive maintenance intervals can be given as follows: 


$$
\sum_{i=1}^{n-1} E C f i(T)=\sum_{i=1}^{n-1} E N r(i) C f
$$

In the same way, the failure number of the product between $K 1+T p+(n-1)\left(T+T_{p}\right)$ and $K$ is expressed as:

$$
\operatorname{ENr}(n)=\int_{K 1+(n-1) T+n T_{p}}^{K} \lambda n(t \mid r) d t .
$$

So the expected warranty cost of the product of the time between $K 1+T_{p}+(n-1)\left(T+T_{p}\right)$ to $\mathrm{K}$ is given as:

$$
E C f n(K 1, K)=E N r(n) C f .
$$

Then, the expected warranty cost can be obtained by inserting eq.(7)-(13) into (6):

$$
\begin{aligned}
E C_{r}^{1}(\varpi)= & C f \int_{0}^{K 1} \lambda(t \mid r) d t+\operatorname{int}\left[\left(K-K 1-T_{p}\right) /\left(T+T_{p}\right)+1\right] C_{p} \\
& +\sum_{i=1}^{n-1} \int_{K 1+(i-1) T+i T_{p}}^{K 1+i\left(T+T_{p}\right)} \lambda_{i}(t \mid r) d t C f+\int_{K 1+(n-1) T+n T_{p}}^{K} \lambda_{n}(t \mid r) d t C_{f} .
\end{aligned}
$$

Availability model: In this case, since the warranty will cease at time $K$, expected availability in the warranty region can be expressed as follows:

$$
E A_{r}^{1}(\varpi)=\frac{K-E D_{r}^{1}(\varpi)}{K}
$$

where $E D_{r}^{1}(\varpi)$ is the expected shutdown time in the warranty region and has the similar expression with $E C_{r}^{1}(\varpi)$ by $\mathrm{T}_{p}$ and $\mathrm{T}_{f}$ replace $\mathrm{C}_{p}$ and $\mathrm{C}_{f}$. So $E D_{r}^{1}(\varpi)$ is given by:

$$
E D_{r}^{1}(\varpi)=T f E N(K 1 \mid r)+n T p+\sum_{i=1}^{n-1} E T f i(T)+E T f n(K 1, K) .
$$

Similarly, $\operatorname{ETf}_{f}(T)$ is the expected shutdown time of minimal repairs in the $i$-th periodic preventive maintenance interval, and $\operatorname{ETfn}_{n}(K 1, K)$ is the expected shutdown time of minimal repairs between $K 1+T p+(n-1)\left(T+T_{p}\right)$ and $K$. The expressions as follows:

$$
\begin{aligned}
& \sum_{i=1}^{n-1} E T_{f i}(T)=\sum_{i=1}^{n-1} E N r(i) T f, \\
& E T f n(K 1, K)=E N r(n) T f .
\end{aligned}
$$

The remaining parameters are the same as in eq.(6). Then, the function of expected availability can be given as follows:
$E A_{r}^{1}(\varpi)=1-\frac{1}{K}\left[\begin{array}{c}T f \int_{0}^{K 1} \lambda(t \mid r) d t+i n t\left[\left(K-K 1-T_{p}\right) /\left(T+T_{p}\right)+1\right] T_{p} \\ +\sum_{i=1}^{n-1} \int_{K 1+(i-1) T+i T_{p}}^{K 1+i\left(T+T_{p}\right)} \lambda_{i}(t \mid r) d t T_{f}+\int_{K 1+(n-1) T+n T_{p}}^{K} \lambda_{n}(t \mid r) d t T_{f}\end{array}\right]$

To facilitate subsequent calculation, the expected cost in the warranty region can be viewed as a function of the decision variables $(K 1$, $T$ ) and the warranty time limit $K$, denote:

$$
E C_{r}^{1}(\varpi) \stackrel{d e f}{=} \phi(K 1, K, T)
$$
by:

Similarly, the expected availability in warranty region is denoted

$$
E A_{r}^{1}(\varpi) \stackrel{d e f}{=} \xi(K 1, K, T) .
$$

\subsubsection{Case (a.2): $r 1<r \leq r 2$}

In this case, due to exceeding the usage limit L1, the warranty over the subregions $\Omega_{1}$ and $\Omega_{2}$ will expire at time points $\tau 1$ and $K$ respectively (see Fig.2). With $\tau 1=L 1 / r$. Then the expected warranty cost for this case becomes:

$$
\begin{aligned}
E C_{r}^{2}(\varpi) & =\phi(\tau 1, K, T) \\
& =C f E N(\tau 1 \mid r)+n C_{p}+\sum_{i=1}^{n-1} E C f i(T)+E C f n(\tau 1, K),
\end{aligned}
$$

where the time limit $K_{1}$ in eq.(6) is replaced by $\tau 1$.

Similarly, the expected availability in the warranty region becomes:

$$
\begin{aligned}
E A_{r}^{2}(\varpi) & =\xi(\tau 1, K, T) \\
& =\left\{K-\left[\operatorname{TfEN}(\tau 1 \mid r)+n T_{p}+\sum_{i=1}^{n-1} E T_{f i}(T)+\operatorname{ETfn}(\tau 1, K)\right]\right\} / K
\end{aligned}
$$

\subsubsection{Case (a.3): $r 2<r$}

In this case, due to exceeding the usage limit $L_{1}$ and $L$, the warranty over the subregions $\Omega_{1}$ and $\Omega_{2}$ will expire at time points $\tau 1$ and $\tau$, respectively (see Fig.2). With:

$$
\tau 1=\frac{L 1}{r}, \tau=\frac{L}{r}
$$

then the expected warranty cost for this case becomes:

$$
\begin{aligned}
E C_{r}^{3}(\varpi) & =\phi(\tau 1, \tau, T) \\
& =C f E N(\tau 1 \mid r)+n C p+\sum_{i=1}^{n-1} E C f i(T)+E C f n(\tau 1, \tau),
\end{aligned}
$$

where the time limit $K_{1}$ and $K$ in eq.(6) is replaced by $\tau 1$ and $\tau$, respectively.

Similarly, the expected availability in the warranty region becomes: 


$$
\begin{aligned}
E A_{r}^{3}(\varpi) & =\xi(\tau 1, \tau, T) \\
& =\left\{\tau-\left[\operatorname{TfEN}(\tau 1 \mid r)+n T_{p}+\sum_{i=1}^{n-1} E T f i(T)+E T f n(\tau 1, \tau)\right]\right\} / \tau .
\end{aligned}
$$

In the end, we remove the conditioning on $R=r$, where $\mathrm{R}$ has distribution function $G(r)$, to get the expected warranty cost for case (a), given by:

$$
E C^{\Omega}(\varpi)=\int_{0}^{r 1} E C_{r}^{1}(\varpi) d G(r)+\int_{r 1}^{r 2} E C_{r}^{2}(\varpi) d G(r)+\int_{r 2}^{\infty} E C_{r}^{3}(\varpi) d G(r) .
$$
by:

Similarly, the expected availability in the warranty region is given $E A^{\Omega}(\varpi)=\int_{0}^{r 1} E A_{r}^{1}(\varpi) d G(r)+\int_{r 1}^{r 2} E A_{r}^{2}(\varpi) d G(r)+\int_{r 2}^{\infty} E A_{r}^{3}(\varpi) d G(r)$.

\subsection{Case1 (b): $r 1>r^{2}$}

For this case, similar to case (a), the following three subcases are considered:

$$
\text { (b.1) } r \leq r 2 \text {; (b.2) } r 2<r \leq r 1 \text {; (b.3) } r 1<r \text {. }
$$

We use the same denotation setting with case (a) to model the expected warranty cost and availability under case (b).

Using eq.(17), the expected warranty cost under the three subcases are given by:

$$
\begin{aligned}
& E C_{r}^{1}(\varpi)=\phi(K 1, K, T), \\
& E C_{r}^{2}(\varpi)=\phi(K 1, \tau, T), \\
& E C_{r}^{3}(\varpi)=\phi(\tau 1, \tau, T) .
\end{aligned}
$$

The expected availability under the three subcases are given by:

$$
\begin{aligned}
& E A_{r}^{1}(\varpi)=\xi(K 1, K, T), \\
& E A_{r}^{2}(\varpi)=\xi(K 1, \tau, T), \\
& E A_{r}^{3}(\varpi)=\xi(\tau 1, \tau, T) .
\end{aligned}
$$

Note that subcases (1) and (3) for case (b) are the same as that for case (a), and the only difference is for subcase (2) since the warranty ceases at distinct time. See Fig. (2).

On removing the conditioning, we have the expected warranty cost given by:

$E C^{\Omega}(\varpi)=\int_{0}^{r 2} E C_{r}^{1}(\varpi) d G(r)+\int_{r 2}^{r 1} E C_{r}^{2}(\varpi) d G(r)+\int_{r 1}^{\infty} E C_{r}^{3}(\varpi) d G(r)$,

accordingly, the expected availability is given by:

$$
E A^{\Omega}(\varpi)=\int_{0}^{r 2} E A_{r}^{1}(\varpi) d G(r)+\int_{r 2}^{r 1} E A_{r}^{2}(\varpi) d G(r)+\int_{r 1}^{\infty} E A_{r}^{3}(\varpi) d G(r) .
$$

\section{Deriving optimum warranty servicing strategy}

Scientific warranty servicing strategy demands to control warranty cost and guarantee availability simultaneously. To derive the optimum warranty servicing strategy, the optimizing model is given as follows:

$$
\left\{\begin{array}{l}
\min \quad E C^{\Omega}(\varpi) \\
\text { s.t. } E A^{\Omega}(\varpi) \geq A_{0} \\
0<K_{1}<K ; 0<T<K-K_{1}
\end{array}\right.
$$

where the decision variable $\varpi=\left(K_{1}, T, r_{1}\right)$. The optimizing model is to minimize the warranty cost on the premise of ensuring the expected availability greater than $A_{0}$, which can derive optimum warranty servicing strategy for both manufacturer and consumer. As the model is difficult to calculate, a grid search in specific regions is performed to obtain the optimum results.

In general, when the $\left(K_{1}, r_{1}\right)$ is fixed, the expected warranty cost $E C^{\Omega}(\varpi)$ will increase first and then decrease with the growth of the preventive maintenance interval $T$, and the expected availability $E A^{\Omega}(\varpi)$ has the opposite trend. Based on the optimizing model proposed above, the following three cases are considered (see Fig.3):

$$
\begin{aligned}
& \text { case (1): } T_{u}<T_{c} \text {, then } T^{*}=T_{u}, \\
& \text { case (2): } T_{l} \leq T_{c} \leq T_{u} \text {, then } T^{*}=T_{c}, \\
& \text { case (3): } T_{c}<T_{l} \text {, then } T^{*}=T_{l},
\end{aligned}
$$

where $T_{l}$ and $T_{u}$ represent the lower and upper limits of PM interval $T$ under $E A^{\Omega}(\varpi) \geq A_{0}$, respectively, and $T_{c}$ is the PM interval to minimize the expected warranty cost without constrains, $T^{*}$ is the optimal solution of the optimizing model under fixed $\left(K_{1}, r_{1}\right)$. Similarly, the values of $T^{*}$ can be obtained under different $\left(K_{1}, r_{1}\right)$, and then, the optimum warranty servicing strategy $\varpi^{*}=\left(K_{1}^{*}, T^{*}, r_{1}^{*}\right)$ and the corresponding $E C^{\Omega}\left(\varpi^{*}\right)$ and $E A^{\Omega}(\varpi)^{*}$ can be derived by comparative analysis. The analytic procedure is analogous for other curve forms.

To obtain more integrated information about the optimum warranty servicing strategy, unit cost-effective of the product is introduced as follows:

$$
E V^{\Omega}(\varpi)=E C^{\Omega}(\varpi) / E \tau E A^{\Omega}(\varpi)
$$

where $E \tau$ is the expected warranty period, and it is given by:

$$
E \tau=K G\left(r_{2}\right)+\int_{r_{2}}^{\infty} L / r d G(r)
$$

The unit cost-effective of the product with optimum warranty servicing strategy can be derived using eq.(31), combining with the optimizing solutions, which can provide scientific information for both manufacturer and consumer. 



Fig. 3. Optimal T under different cases

\section{An example}

Considering an automobile component sold with a free-repair warranty policy, we will pay attention to the warranty cost from the manufacturer perspective and the availability from the consumer perspective. Assume $K=3$ (3 years) and $L=3\left(30000 \mathrm{~km}\right.$ ), so $r_{2}=L / K=1$.

And the acceptable lower limit of availability is $A_{0}=0.92$.

For the convenience of calculation, let improvement factors $\alpha i=\alpha$, that is each PM actions corresponding the same improvement factor. Commonly, the PMs duration $T_{p}$ is less than the minimal repair duration $T_{f}$, and $C_{p} \leq C_{f}$. The $C_{f}$ and $T_{f}$ are assumed to be constant with the value 1 and 0.02 respectively; then, $C_{p}$ and $T_{p}$ are assumed to be the function of improvement factor $\alpha$, as follows:

$$
C_{p}=C 0+C \alpha^{\beta} \text {, and } T_{p}=\alpha T_{f}=0.02 \alpha .
$$

The expression shows the cost of preventive maintenance will increase exponentially with the growth of improvement factor. In this instance, let $C 0=0.1, C=1$ and $\beta=3$.

In this example, as in [5], we consider the form for the initial conditional failure intensity given by eq.(2), as follows:

$$
\begin{aligned}
\lambda(t \mid r) & =\theta 0+\theta 1 r+\theta 2 T(t)+\theta 3 U(t) \\
& =0.1+0.2 r+(0.7+0.7 r) t^{2}
\end{aligned}
$$

The distribution of usage rate can be estimated using the real data. In this study, the following two distributions are considered:
Normal: $\mathrm{R} \sim \mathrm{N}[1,0.46]$,

Excessive: $\mathrm{R} \sim \mathrm{N}[2,0.86]$.

To see the impact of different usage rate distribution forms on the warranty servicing strategy, a uniform distribution is given to make a comparison:

$$
\mathrm{R} \sim \text { uniform }[0.2,1.8] \text { with } \mathrm{E}(\mathrm{R})=1, \mathrm{D}(\mathrm{R})=0.46 .
$$

For different values of $\alpha$ and for each of the three usage categories, a grid search is performed to find the optimal decision variables denoted by $\varpi^{*}=\left(K_{1}^{*}, T^{*}, r_{1}^{*}\right)$ using the optimizing model in section 5. The variable $K_{1}$ and $T$ are increasing in steps of 0.1 over the interval $[0,3]$ and $[0.1,3]$, respectively. For convenience, the value of rate parameter $r_{1}$ is increasing in steps of 0.2 starting 0.2 , and the remaining cases can be calculation in the same way.

Using the mathematical model and optimization procedure proposed above, the optimal values of $E C^{\Omega}(\varpi)$ and $E A^{\Omega}(\varpi)^{*}$ can be obtained for the three usage categories. Fig.4 shows the values of expected warranty cost and availability with normal usage, as $r_{1}=1$ and $\alpha=0.6$.
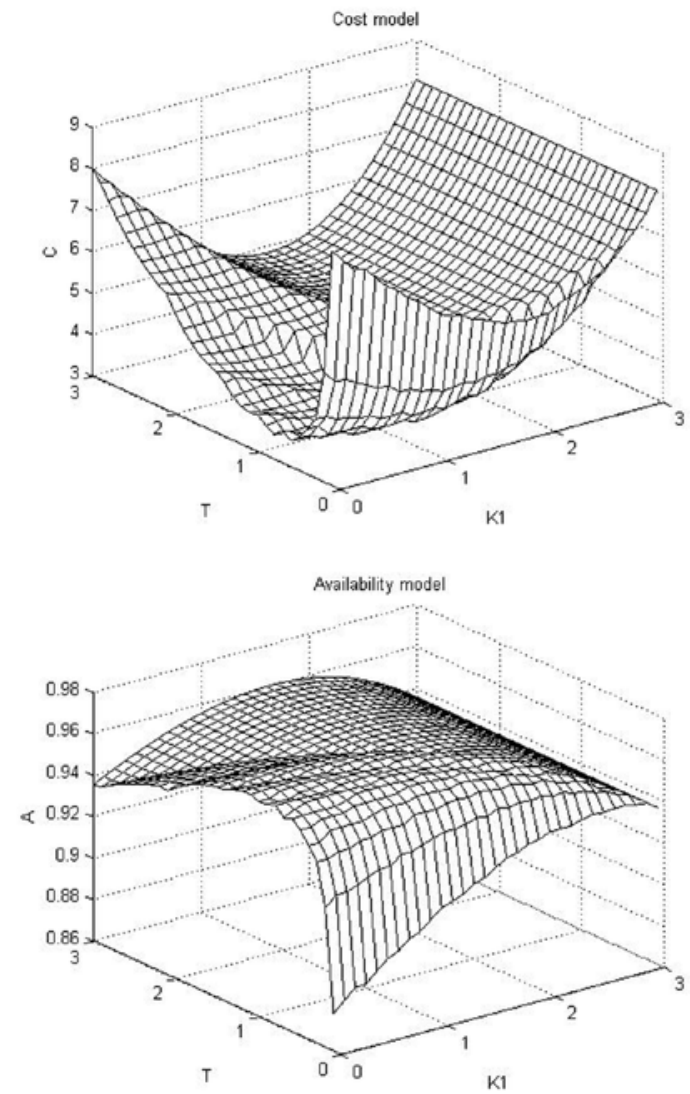

Fig. 4. Grid patterns of cost and availability functions

Let $K_{1}=0.6$, the warranty cost and availability trends can be derived by dimension reduction analysis to Fig.4, as shown in Fig.5. Obviously, it matches case (2) proposed in section 5, so $T^{*}=T_{c}$.

Similarly, we can derive the corresponding optimal results with different $r_{1}$ and $\alpha$ under different usage categories, and the summary of these results is shown in Table 1-Table 4.

Firstly, the two usage categories under normal distribution are considered and the results are presented in Table 1-Table 3. 




Fig. 5. The warranty cost and availability trends

In Table 1, the minimum cost-effective of unit time $E V^{\Omega}\left(\varpi^{*}\right)$ under different improvement factors is given in column 4 , and the correspondingly optimal expected warranty cost $E C^{\Omega}\left(\varpi^{*}\right)$ and availability $E A^{\Omega}(\varpi)^{*}$ are given in columns 2-3. Columns 5-6 present the minimum warranty cost $E C_{0, T}$ and maximum availability $E A_{0, T}$ when $K_{1}=0$, that is, the periodic PMs are implemented during the whole warranty period. The last two columns present the minimum warranty cost $E C_{M R}$ and maximum availability $E A_{M R}$ without PM actions in warranty region. The notations in Table 2 are the same as in Table 1.

Optimal warranty servicing strategy and corresponding cost and availability in each row are printed in boldface in Table 1-Table 3. The following results can be obtained by analyzing these tables:

For each of the two usage categories, The warranty cost $E C^{\Omega}\left(\varpi^{*}\right)$ is always less than $E C_{0, T}$ and $E C_{M R}$, and the availability $E A^{\Omega}\left(\varpi^{*}\right)$ always higher than $E A_{0, T}$ and $E A_{M R}$ under different $\alpha$ values, which leads to a relatively lower unit efficient cost under the warranty servicing strategy introduced in section 2. For example, for the excessive usage category, when $\alpha=0.7$, the warranty cost under the combination strategy can be reduced by $55.1 \%$ and $7.4 \%$ compared adopting the minimal repair or periodic preventive maintenance alone, respectively, and the corresponding availability has an increase of $3.4 \%$ and $0.2 \%$.

The values of unit efficient cost are decreasing firstly and then increasing with the rise of improvement factor. The optimal value is obtained when $\alpha=0.5$ for normal usage and $\alpha=0.7$ for excessive usage, which indicates that it is worthy to perform a better degree of imperfect preventive maintenance with high usage rates.

Table 1 Optimization results for the normal usage rate under different $a$

\begin{tabular}{|c|c|c|c|c|c|c|c|}
\hline$a$ & $E C^{\Omega}\left(\varpi^{*}\right)$ & $E A^{\Omega}\left(\varpi^{*}\right)$ & $E V^{\Omega}\left(\varpi^{*}\right)$ & $E C_{0, T}$ & $E A_{0, T}$ & $E C_{M R}$ & $E A_{M R}$ \\
\hline 0.1 & 6.7394 & 0.9383 & 2.9172 & 6.7573 & 0.9364 & \multirow{9}{*}{8.0017} & \multirow{9}{*}{0.9347} \\
\hline 0.2 & 5.6044 & 0.9406 & 2.4200 & 5.6375 & 0.9368 & & \\
\hline 0.3 & 4.3174 & 0.9487 & 1.8483 & 4.3352 & 0.9441 & & \\
\hline 0.4 & 3.8647 & 0.9549 & 1.6438 & 3.9238 & 0.9506 & & \\
\hline 0.5 & 3.5530 & 0.9604 & 1.5025 & 3.6726 & 0.9594 & & \\
\hline 0.6 & 3.5844 & 0.9606 & 1.5155 & 3.6285 & 0.9598 & & \\
\hline 0.7 & 3.5852 & 0.9608 & 1.5155 & 3.6815 & 0.9602 & & \\
\hline 0.8 & 3.6323 & 0.9611 & 1.5350 & 3.7327 & 0.9606 & & \\
\hline 0.9 & 3.7662 & 0.9612 & 1.5914 & 3.8216 & 0.9609 & & \\
\hline
\end{tabular}

Table 2. Optimization results for the excessive usage rate under different $a$

\begin{tabular}{|c|c|c|c|c|c|c|c|}
\hline$a$ & $E C^{\Omega}\left(\bar{\omega}^{*}\right)$ & $E A^{\Omega}\left(\omega^{*}\right)$ & $E V^{\Omega}\left(\omega^{*}\right)$ & $E C_{0, T}$ & $E A_{0, T}$ & $E C_{M R}$ & $E A_{M R}$ \\
\hline 0.1 & 2.6446 & 0.9302 & 2.2312 & 2.6589 & 0.9298 & \multirow{9}{*}{3.7121} & \multirow{9}{*}{0.9286} \\
\hline 0.2 & 2.2884 & 0.9310 & 1.9346 & 2.3106 & 0.9309 & & \\
\hline 0.3 & 2.0496 & 0.9397 & 1.7072 & 2.0725 & 0.9395 & & \\
\hline 0.4 & 1.8773 & 0.9472 & 1.5569 & 1.9204 & 0.9470 & & \\
\hline 0.5 & 1.7712 & 0.9535 & 1.4610 & 1.8181 & 0.9533 & & \\
\hline 0.6 & 1.6850 & 0.9586 & 1.3846 & 1.8097 & 0.9585 & & \\
\hline 0.7 & 1.6647 & 0.9603 & 1.3691 & 1.7971 & 0.9587 & & \\
\hline 0.8 & 1.7078 & 0.9601 & 1.4006 & 1.8539 & 0.9587 & & \\
\hline 0.9 & 1.8120 & 0.9596 & 1.4868 & 1.9854 & 0.9584 & & \\
\hline
\end{tabular}


Table 3. Optimal warranty servicing strategy for the two usage categories under normal distribution

\begin{tabular}{|c|c|c|c|c|c|c|}
\hline Usage category & a & $\mathrm{K}_{1}^{*}$ & $\mathrm{~L}_{1}^{*}$ & $\mathrm{~T}^{*}$ & $r_{1}{ }^{*}$ & $E V^{\Omega}\left(\omega^{*}\right)$ \\
\hline \multirow{9}{*}{ Normal } & 0.1 & 0.7 & 0.70 & 0.2 & 1.0 & 2.9172 \\
\hline & 0.2 & 0.8 & 0.80 & 0.2 & 1.0 & 2.4200 \\
\hline & 0.3 & 0.7 & 0.70 & 0.3 & 1.0 & 1.8483 \\
\hline & 0.4 & 0.9 & 0.90 & 0.5 & 1.0 & 1.6438 \\
\hline & 0.5 & 1.0 & 1.00 & 0.5 & 1.0 & 1.5025 \\
\hline & 0.6 & 0.9 & 0.90 & 0.7 & 1.0 & 1.5155 \\
\hline & 0.7 & 1.2 & 1.20 & 0.6 & 1.0 & 1.5155 \\
\hline & 0.8 & 1.1 & 1.10 & 0.7 & 1.0 & 1.5350 \\
\hline & 0.9 & 1.3 & 1.30 & 0.7 & 1.0 & 1.5914 \\
\hline \multirow{9}{*}{ Excessive } & 0.1 & 1.5 & 0.60 & 0.3 & 0.4 & 2.2312 \\
\hline & 0.2 & 1.6 & 0.64 & 0.2 & 0.4 & 1.9346 \\
\hline & 0.3 & 1.1 & 0.66 & 0.3 & 0.6 & 1.7072 \\
\hline & 0.4 & 1.3 & 0.78 & 0.4 & 0.6 & 1.5569 \\
\hline & 0.5 & 1.6 & 0.96 & 0.5 & 0.6 & 1.4610 \\
\hline & 0.6 & 1.5 & 0.90 & 0.6 & 0.6 & 1.3846 \\
\hline & 0.7 & 1.2 & 0.96 & 0.6 & 0.8 & 1.3691 \\
\hline & 0.8 & 0.8 & 0.80 & 0.6 & 1.0 & 1.4006 \\
\hline & 0.9 & 1.2 & 1.20 & 0.6 & 1.0 & 1.4868 \\
\hline
\end{tabular}

Table 4. Optimal warranty servicing strategy for different usage rate distributions

\begin{tabular}{|c|c|c|c|c|c|}
\hline Distribution forms & $a$ & $\mathrm{~K}_{1}^{*}$ & $\mathrm{~T}^{*}$ & $r_{1}{ }^{*}$ & $E V^{\Omega}\left(\varpi^{*}\right)$ \\
\hline \multirow{9}{*}{ Normal distribution } & 0.1 & 0.7 & 0.2 & 1.0 & 2.9172 \\
\hline & 0.2 & 0.8 & 0.2 & 1.0 & 2.4200 \\
\hline & 0.3 & 0.7 & 0.3 & 1.0 & 1.8483 \\
\hline & 0.4 & 0.9 & 0.5 & 1.0 & 1.6438 \\
\hline & 0.5 & 1.0 & 0.5 & 1.0 & 1.5025 \\
\hline & 0.6 & 0.9 & 0.7 & 1.0 & 1.5155 \\
\hline & 0.7 & 1.2 & 0.6 & 1.0 & 1.5155 \\
\hline & 0.8 & 1.1 & 0.7 & 1.0 & 1.5350 \\
\hline & 0.9 & 1.3 & 0.7 & 1.0 & 1.5914 \\
\hline \multirow{9}{*}{ Uniform distribution } & 0.1 & 0.7 & 0.2 & 1.0 & 2.9802 \\
\hline & 0.2 & 0.7 & 0.2 & 1.0 & 2.4739 \\
\hline & 0.3 & 0.8 & 0.3 & 1.0 & 2.0782 \\
\hline & 0.4 & 0.7 & 0.4 & 1.0 & 1.7656 \\
\hline & 0.5 & 0.7 & 0.5 & 1.0 & 1.5429 \\
\hline & 0.6 & 0.8 & 0.6 & 1.0 & 1.3930 \\
\hline & 0.7 & 0.9 & 0.7 & 1.0 & 1.2689 \\
\hline & 0.8 & 0.9 & 0.7 & 1.0 & 1.2848 \\
\hline & 0.9 & 1.0 & 1.0 & 1.0 & 1.3054 \\
\hline
\end{tabular}

The optimal parameters related to warranty servicing strategy are given in Table 3, which include the usage limit and age limit of $\Omega_{1}$ and preventive maintenance period $\mathrm{T}$. It can be seen from the table that:

In most cases, the $r_{1}{ }^{*}$ under normal usage is greater than under excessive usage, that is to say, the shape of the minimal repair region $\Omega_{1}$ is relatively flat and with a lower usage limit under excessive usage for a fixed $\alpha$. It can be also noticed that the usage limit of region
$\Omega_{1}$ has a growth trend when the improvement factors increase. The optimal warranty servicing strategies are printed in boldface.

Table 4 shows the optimal warranty servicing strategy and the value of unit efficient cost under normal distribution $(\mathrm{R} \sim \mathrm{N}[1,0.46])$ and uniform distribution $(\mathrm{R} \sim$ uniform $[0.2,1.8])$. As presented in this table, although the expectation and variation of the two distributions are identical, there are obvious differences in the optimal results, so it is important to confirm reasonable distribution according to reality before making warranty servicing strategy. 
Table 1-Table 4 include the balance of the needs and interests between the manufacture and the consumer under different imperfect PM improvement factor, the corresponding calculation results as warranty cost, the availability and unit efficient cost, which can provide scientific reference for selecting the reasonable warranty servicing strategy to balance the benefit of manufacturer and consumer.

In addition, for the convenience of implement or maintenance capacity constraints reasons, the PM's period $T$ or improvement factor $\alpha$ may be a limited value in reality, then we can also derive the optimum warranty servicing strategy using the mathematical model proposed in this paper (as shown in Fig. 4).

\section{Conclusions}

In this paper, a strategy combining the imperfect preventive maintenance and minimal repair is proposed under the free repair warranty policy, then warranty cost and availability models are built, and optimum warranty servicing strategies are identified with respect to both warranty cost and product availability. We provide a numerical illustration to show the optimization method and accurate calculation results under different strategies and make a comparison, which can offer a reference to select the optimum warranty servicing strategy benefiting both manufacturer and consumer.

The result of this paper can be extended in several ways. One possible extension is to consider the preventive maintenance under pro-rata warranty policy since the PMs can improve the product availability and benefit to consumer. Another option for generalization is to develop the functional relationship between the product availability and sales, and then, make the optimum warranty servicing strategy.

\section{Acknowledgement}

The research work is supported by the National Natural Science Foundation of China with contract number 70971135.

\section{References}

1. Blischke W R, Murthy D N P. Warranty cost analysis. New York: CRC Press, 1994.

2. Hun Y H. Optimal number of periodic preventive maintenance operations under warranty. Reliability Engineering and System Safety 1992; 37(3): 223-225, http://dx.doi.org/10.1016/0951-8320(92)90127-7.

3. Doyen L, Gaudoin O. Classes of imperfect repair models based on reduction of failure intensity or virtual age. Reliability Engineering and System Safety 2004; 84(1): 45-56, http://dx.doi.org/10.1016/S0951-8320(03)00173-X.

4. Guo J, Fei H. An optimal preventive maintenance policy for product sold with warranty. Journal of Mathematics 2009; 29(4): 546-550.

5. Iskandar B P, Murthy D N P, Jack N. A new repair-replace strategy for items sold with a two-dimensional warranty, Computers and Operations Research 2005; 32 (3): 669-682, http://dx.doi.org/10.1016/j.cor.2003.08.011.

6. Iskandar B P, Murthy D N P. Repair-replace strategies for two-dimensional warranty policies. Mathematical and Computer Modelling 2003; 38: 1233-1241, http://dx.doi.org/10.1016/S0895-7177(03)90125-7.

7. Jack N, Dagpunar J S. An optimal imperfect maintenance policy over a warranty period. Microelectronics and Reliability 1994; 34(3): 529534, http://dx.doi.org/10.1016/0026-2714(94)90091-4.

8. Murthy D N P, Iskandar B P, Wilson R J. Two-dimensional failure free warranties: Two-dimensional point process models. Operations Research 1995; 43: 356-366, http://dx.doi.org/10.1287/opre.43.2.356.

9. Tsai Y, Wang K, Tsai L. A study of availability-centered preventive maintenance for multi-component systems. Reliability Engineering and System Safety 2004; 84(3): 261-270, http://dx.doi.org/10.1016/j.ress.2003.11.011.

10. Varnosafaderani S, Chukova S. An imperfect repair strategy for two-dimensional warranty. Journal of the Operational Research Society, 2012; 63(6): 846-859,http://dx.doi.org/10.1057/jors.2011.66.

11. Varnosafaderani S, Chukova S. A two-dimensional warranty servicing strategy based on reduction in product failure intensity. Computers and Mathematics with Applications 2012; 63: 201-213, http://dx.doi.org/10.1016/j.camwa.2011.11.011.

12. Yeh R H, Lo H C. Optimal preventive maintenance warranty policy for repairable products. European Journal of Operational Research 2001; 134(1): 59-69, http://dx.doi.org/10.1016/S0377-2217(00)00238-1.

13. Yun W Y, Kang K M. Imperfect repair policies under two-dimensional warranty. Proceedings of the Institution of Mechanical Engineers 2007; 221(4): 239-247, http://dx.doi.org/10.1243/1748006XJRR55.

\section{Zhonghua CHENG \\ Zhiyuan YANG \\ Jianmin ZHAO \\ Yabin WANG \\ Zhiwei LI}

Department of Management Engineering

Mechanical Engineering College

Shijiazhuang, Hebei, 050003, P.R. China

E-mail: zszs197466@163.com,yzy_sjz90@126.com,jm_zhao@

hotmail.com,wangyabin123@163.com,arhqs@126.com 